\title{
Nutrient release characteristics from droppings of grass- foraging waterfowl (Anser brachyrhynchus) roosting in aquatic habitats
}

\author{
Yuhong Liu, ${ }^{1,2,4 *}$ Mariet M. Hefting, ${ }^{1}$ Jos T. A. Verhoeven ${ }^{1}$ and Marcel Klaassen ${ }^{1,3,4 *}$ \\ ${ }^{1}$ Ecology and Biodiversity, Institute of Environmental Biology, Utrecht University, Padualaan 8, Utrecht NL-3584 CH, The Netherlands \\ ${ }^{2}$ Yantai Institute of Coastal Zone Research, CAS, 17 Chunhui Rd, Laishan, Yantai, Shandong 264003, China \\ ${ }^{3}$ Centre for Integrative Ecology, Deakin University, Locked Bag 20000 Geelong, Victoria 3220, Australia \\ ${ }^{4}$ Netherlands Institute of Ecology (NIOO-KNAW), PO Box 50, Wageningen NL-6700 AB, The Netherlands
}

\begin{abstract}
In recent decades, notably in large parts of the Western World, many waterfowl populations have increased because of increased food availability. Not uncommonly, eutrophication in these areas may occur perhaps not only because of increased dropping loads but also because nutrients are more readily released from droppings than from fresh and decomposing plant material. We conducted an experiment to study this effect comparing the decay rate and nutrient release of fresh grass leaves with that of droppings in water at 10,20 and $30^{\circ} \mathrm{C}$. Using a two-component exponential decay model, allowing distinguishing between an easily decomposable (labile) and recalcitrant fraction of the material, we found that the labile carbon (C) fraction of droppings decomposed faster than that of grass leaves, whereas the recalcitrant $\mathrm{C}$ decomposition rate was similar to that of grass leaves. Higher temperature increased $\mathrm{C}$ decomposition rates of the labile fractions. No temperature dependence was observed for the recalcitrant fractions. Surprisingly, grass leaves and droppings did not differ in the amounts of nitrogen $(\mathrm{N})$ and phosphorus $(\mathrm{P})$ released in the first 90 days, i.e. more than $60 \%$ of $\mathrm{N}$ and $40 \%$ of $\mathrm{P}$ were released into the water column. Continuous mineralization of $\mathrm{N}$ and $\mathrm{P}$ predominated during decomposition of grass leaves, whereas a massive initial leaching was followed by immobilization and later mineralization during decomposition of droppings. All differences during decomposition of the litter types were attributed to the stoichiometric requirement of decomposers and their temperature sensitivity. Copyright (C) 2013 John Wiley \& Sons, Ltd.
\end{abstract}

KEY WORDS decomposition; net mineralization; waterfowl droppings; allochthonous nutrient input

Received 12 March 2013; Revised 24 October 2013; Accepted 24 October 2013

\section{INTRODUCTION}

Grazing may increase the rate of nutrient cycling and thus enhance nutrient availability, as has been well documented in terrestrial systems (Bazel and Jefferies, 1985). The stimulating effect depends on nutrients, typically nitrogen $(\mathrm{N})$ and phosphorus $(\mathrm{P})$, becoming more readily available for primary production through release from the grazers' droppings. A similar effect of increased nutrient cycling may apply to shallow lakes with abundant macrophyte growth attracting foraging herbivorous waterfowl. Nutrient availability in some water bodies may increase through the attraction of large numbers of waterfowl that forage terrestrially and subsequently defecate while roosting in

*Correspondence to: Yuhong Liu and Marcel Klaassen, Yantai Institute of Coastal Zone Research, CAS, 17 Chunhui Rd, Laishan, Yantai, Shandong 264003, China, and Centre for Integrative Ecology, Deakin University, Locked Bag 20000 Geelong, Victoria 3220, Australia.

E-mail: yu_hong_liu@263.net; marcel.klaassen@deakin.edu.au the water (Post et al., 1998). Locally, internal nutrient cycling and allochthonous nutrient input by waterfowl may have significant effects on the functioning of aquatic systems (Kitchell et al., 1999).

Over the past decades, and notably so in Europe and North America, considerable improvement in water quality of many shallow freshwater systems has been witnessed, attracting increasing numbers of resident waterfowl that extensively forage on the newly formed aquatic macrophyte beds (e.g. Klaassen and Nolet, 2007; O’Hare et al., 2007; Hahn et al., 2008). At the same time, some of these water bodies are important as a winter haven for large numbers of predominantly terrestrially foraging herbivorous waterfowl (notably geese and ducks) (Mayes, 1991; Gill, 1996; Madsen et al., 1999). An important driving force for the increase in waterfowl roosting in these shallow water bodies are modern agricultural practices that provide nearby high-quality food for herbivorous birds (Van Eerden et al., 1996). These developments raise the awareness of the potentially increasing local role of 
waterfowl in the nutrient dynamics of aquatic habitats. Crucial to our understanding of this role is the rate at which nutrients from droppings are released to the water column and are thus made available to the aquatic ecosystem.

There are many experiments that describe the rate of release of chemical constituents as a result of macrophyte litter decomposition in water (e.g. Kirschner et al., 2001; Chimney and Pietro, 2006). However, the effects of macrophyte-grazing waterfowl on nutrient availability in the water column of lakes have been little studied. We know of only one relevant study in this respect, where the direct addition of goose droppings to mesocosms did not, however, result in any measurable increase in nutrient availability. As an explanation for this effect, the quick settling of droppings to the sediment was held responsible (Unckless and Makarewicz, 2007). Alternatively, the nutrients might also have been readily absorbed by the various organisms in the system. Another study on quantification of allochthonous nutrient inputs to water systems by herbivorous waterfowl was based on a simple input and output model (Hahn et al., 2008). In this model, 'input' is formed by the nutrients in consumed food such as plant leaves and 'output' by the nutrients in waterfowl droppings. However, the study did not consider details of nutrient release in water and simply assumed all nutrients entering the water in droppings to be readily available. Thus, little information appears to be available on the rate at which nutrients from waterfowl droppings become available to the autotrophs in aquatic systems.

We here report on an experiment in which we measured nutrient release to the water column during decomposition of submerged fresh grass leaves of Perennial Ryegrass (Lolium perenne), often used as food by terrestrial feeding waterfowl grazing on managed pastures, and submerged droppings of Pink-footed Geese (Anser brachyrhynchus) that had been feeding on leaves of the same grass species. We chose to use fresh grass leaves and droppings because we wanted to compare the decomposition characteristics of both digested and undigested materials assuming the pathway of nutrient release from these materials into the water would be different. Moreover, we conducted decomposition trials with fresh grass leaves and droppings at three different incubation temperatures of 10,20 and $30{ }^{\circ} \mathrm{C}$ to simulate seasonal effects on decomposition and mineralization rates. Our main objectives were the following: (1) to study the difference in nutrient release from digested and undigested terrestrial plant leaves in the context of allochthonous nutrient input to freshwater ecosystems; (2) to provide information on the effect of water temperature on these nutrient release patterns; and (3) therewith to test if droppings could be a potential menace of $\mathrm{N}$ and $\mathrm{P}$ enrichment to the health of aquatic ecosystems.

\section{MATERIALS AND METHODS}

\section{Experimental design}

Fresh droppings containing both faeces and urinary waste products (i.e. almost exclusively uric acid) from terrestrially feeding Pink-footed Geese and fresh leaves of the vegetation on which these birds foraged, mainly terrestrial grassland dominated by L.perenne, were collected in a meadow near Oudega, the Netherlands $\left(52^{\circ} 59^{\prime} 23^{\prime \prime} \mathrm{N}, 05^{\circ}\right.$ $32^{\prime} 50^{\prime \prime} \mathrm{E}$ ) on 21 October 2008. Droppings were pooled and homogenized in the laboratory. Fresh L.perenne leaves were cut into 2 -cm-long pieces. Ten grammes of homogenized fresh droppings or $5 \mathrm{~g}$ of fresh leaves, corresponding to equal initial dry weights of approximately $1 \mathrm{~g}$, were placed in plastic coffee cups to which $100 \mathrm{ml}$ of filtered (mesh size $100 \mu \mathrm{m}$ ) lake water collected from Lake Maarsseveen $\left(52^{\circ} 12^{\prime} 17^{\prime \prime} \mathrm{N}, 04^{\circ} 57^{\prime} 14^{\prime \prime} \mathrm{E}\right)$ was added to allow for inoculation with microbes necessary to initiate decomposition. Cups were placed in climate chambers in the dark, at 10,20 and $30{ }^{\circ} \mathrm{C}$ at the Netherlands Institute of Ecology in Nieuwersluis, The Netherlands. All samples were collected in the field, processed in the lab and placed to incubate within 1 day. During the experiment, distilled water was regularly added to compensate for evaporative water loss. On day $0,1,2,3,5,10,17,30,52$ and 92, we measured the effect of decomposition by quantifying the remaining plant and droppings in a total of five cups per treatment combination (i.e. material $\times$ time $\times$ temperature). Remaining plant material was collected by filtering the cup contents through a $2 \mu \mathrm{m}$ filter. Remaining dropping material was collected by centrifuging the cup contents at $6000 \mathrm{rpm}$ for $10 \mathrm{~min}$ after which the liquid was removed using a syringe with a $2 \mu \mathrm{m}$ filter tip. All remaining material was immediately dried at $70{ }^{\circ} \mathrm{C}$ for $48 \mathrm{~h}$ until constant weight. After drying, samples were weighed, ground and stored in glass vials.

\section{Laboratory methods}

A small fraction of each dried sample (approximately $0.25 \mathrm{mg}$ ) was analysed for carbon (C) and $\mathrm{N}$ content using a HEKAtech EuroEA elemental analyser. The remaining fraction of the sample was treated with a salicylic acid thiosulphate modification of the Kjeldahl digestion method (Bremner and Mulvaney, 1982) after which P concentration was determined colorimetrically on a continuous flow analyser (Skalar SA-40).

\section{Data analysis}

The amounts of $\mathrm{C}, \mathrm{N}$ and $\mathrm{P}$ remaining were expressed relative to the initial amounts of these nutrients (\%) (Table I) to document losses and gains of these elements during the experiment. Decomposition and nutrient dynamics data were fitted to a two-component exponential 
Table I. Initial composition of fresh grass leaves (Lolium perenne) and Pink-footed Geese (Anser brachyrhynchus) droppings.

\begin{tabular}{lrrrrr}
\hline Content & \multicolumn{2}{c}{ Grass leaves } & & \multicolumn{2}{c}{ Droppings } \\
\cline { 2 - 3 } \cline { 6 - 6 }$(\%)$ & Mean & SD & & Mean & SD \\
\hline Water & 84.83 & 0.25 & & 88.90 & $0 \cdot 18$ \\
Carbon & 41.73 & 0.44 & & $35 \cdot 33$ & $2 \cdot 17$ \\
Nitrogen & 3.24 & 0.17 & & 4.00 & 0.26 \\
Phosphorus & 0.40 & 0.02 & & 0.36 & 0.03 \\
\hline
\end{tabular}

SD, standard deviation.

Water as percentage of total wet weight, and carbon, nitrogen and phosphorus as percentage of total dry weight.

decay model for the three different temperatures and both droppings and fresh plant material separately. This model allows for the decomposing material to be partitioned into a relatively labile fraction $\left(P_{l a b}\right)$, and a more recalcitrant fraction $\left(P_{0^{-}} P_{l a b}\right)$, and that each fraction decays exponentially (Brock et al., 1985; Truesdale et al., 2005):

$$
\begin{aligned}
W(t)= & \left(P_{0}-P_{l a b}\right) \bullet \exp \left(-K_{r e c} \bullet t\right) \\
& +P_{l a b} \bullet \exp \left(-K_{l a b} \bullet t\right)
\end{aligned}
$$

where $W(t)(\%)$ is the percentage of the dry mass remaining relative to the initial dry mass after time interval $t(\mathrm{~d}), P_{O}$ is a total percentage of the initial dry mass $(100 \%), P_{l a b}$ is the labile fraction percentage, $P_{0^{-}} P_{l a b}$ is the recalcitrant fraction percentage, $K_{l a b}$ is the decomposition rate constant of the labile fraction $\left(d^{-1}\right)$ and $K_{\text {rec }}$ is the decomposition rate constant of the recalcitrant fraction $\left(d^{-1}\right)$. The twocomponent exponential decay model was fit to the data to estimate values for parameters $P_{l a b}, K_{r e c}$ and $K_{l a b}$ using the nonlinear regression function in R (R-Development-CoreTeam 2010). Where a trend was observed in $K_{l a b}$ with temperature, $K_{l a b}$ was replaced with a temperature $\left(T,{ }^{\circ} \mathrm{C}\right)$ dependent exponential function:

$$
\begin{aligned}
W(t)= & \left(P_{0}-P_{l a b}\right) \bullet \exp \left(-K_{r e c} \bullet t\right) \\
& +P_{l a b} \bullet \exp \left(-K^{o}{ }_{l a b} \bullet \exp \left(K^{T}{ }_{l a b} \bullet T\right) \bullet t\right)
\end{aligned}
$$

where $K_{l a b}^{o}$, is the initial decomposition rate constant of the labile fraction and $K_{\text {lab }}^{T}$ is the decomposition rate constant of the labile fraction indifferent temperatures $\left(d^{-1}\right)$. Parameters $P_{l a b}, K_{r e c}, K_{l a b}^{o}$ and $K_{l a b}^{T}$ were estimated with nonlinear regression function using the combined data across all three temperatures.

Although generally nutrient release patterns deviate from decay patterns of weight and $\mathrm{C}$ loss, we assumed that an immediate mineralization of nutrient occurs after a quick leaching phase for the fresh grass leaves and droppings used in this study, because the average C:N and C:P ratio's (13:1 and $100: 1$, respectively) of these two materials were far below the theoretical lowest critical threshold calculated for net nutrient immobilization (C:N 20:1, C:P 350:1)
(Enwezor, 1976; Berg et al., 2006; Moore et al., 2006; Manzoni et al., 2010). And we assumed that the twocomponent exponential decay model, which is generally only used for mass loss and $\mathrm{C}$ mineralization, would also be useful in describing the nutrient dynamics patterns of the droppings and fresh leaves.

For the cases where a two-component exponential model could not be fit, a two-way analysis of variance (ANOVA) of $W(t)$ with $t$ and $T$ as fixed factors was conducted followed by a Tukey post-hoc test to study the effect of temperature, using the functions ANOVA and Tukey's honestly significant difference (Tukey HSD) in R (R-Development-Core-Team, 2010).

\section{RESULTS}

\section{Decomposition rates of grass leaves and droppings at various water temperatures}

Visual inspection of the data suggested that temperature had a clear effect on the decomposition of organic compounds in grass leaves (Figure 1) and droppings (Figure 2). Also comparing the parameter estimates of the two-component exponential decay model (Equation (1)) for the three different temperatures, a clear trend with temperature was evident in the decomposition rate of the labile $C$ fraction, $K_{l a b}$, for both grass leaves (Table II) and droppings (Table III). The subsequent fitting of a twocomponent exponential decay model with a temperaturedependent exponential function for the decomposition rate of the labile C fraction (Equation (2)), also resulted in a significant fit for both grass leaves (Table II) and droppings (Table III). This further proved that increasing temperature benefited the decomposition of the labile $\mathrm{C}$ fraction. Although the average labile $\mathrm{C}$ fraction of grass leaves $\left(P_{l a b}\right)$ tended to be slightly larger than that of droppings [95\% confidence intervals of $P_{l a b}$ in the combined temperature model of grass leaves (Table II) and droppings (Table III) are nonoverlapping], the digestion of terrestrial plant leaves by geese had little effect on the rate of organic compound decomposition, because only for $K_{l a b}$ at $20{ }^{\circ} \mathrm{C}$ were the $95 \%$ confidence interval for grass leaves (Table II) and droppings (Table III) nonoverlapping.

\section{Release of nutrients}

The $\mathrm{N}$ and $\mathrm{P}$ dynamics during decomposition differed considerably with temperature and between grass leaves (Figure 1) and droppings (Figure 2) to the extent that a twocomponent exponential decay model could only be fit to the $10{ }^{\circ} \mathrm{C} \mathrm{N}$ data and none of the $\mathrm{P}$ data for the droppings (Table III), whereas it could successfully be fitted to all the mineralization data of the grass leaves (Table II).

For grass leaves, about $65 \% \mathrm{~N}$ and $55 \% \mathrm{P}$ were released into the water column relatively quickly over the initial decay period from day 0 to day 10 ( $P_{\text {lab }}$ values for $\mathrm{N}$ and $\mathrm{P}$ 

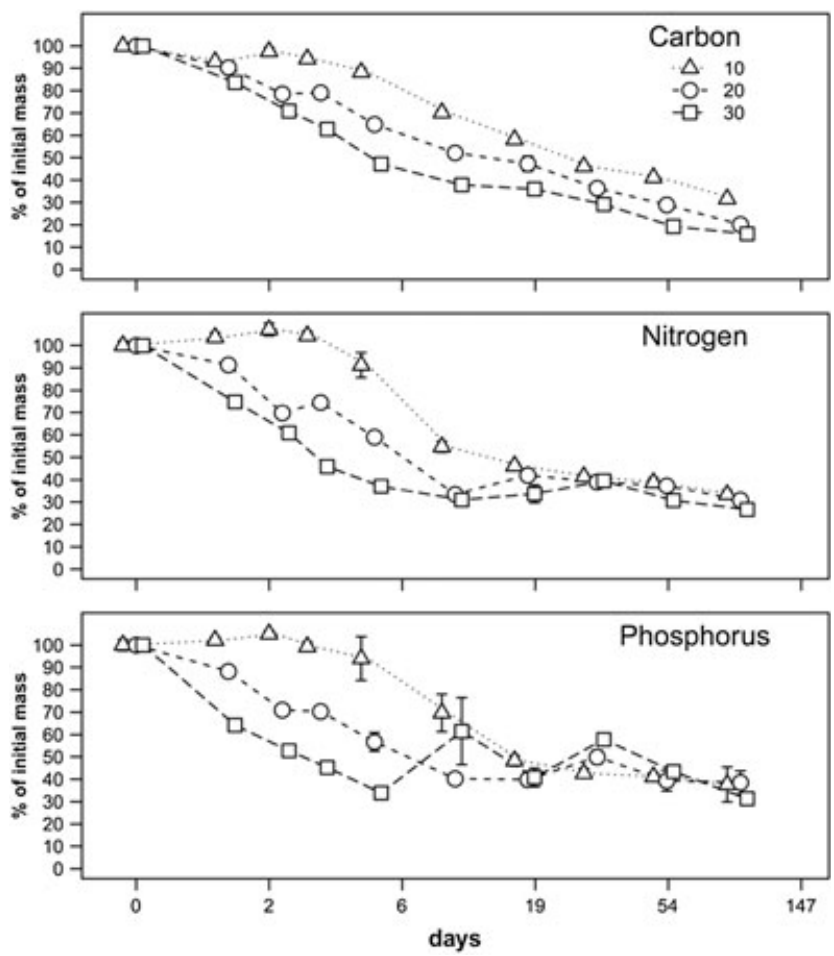

Figure 1. Decomposition patterns of carbon, nitrogen and phosphorus [as $\%$ of initial mass (Table I)] over time (days on a 10-log scale) of grass leaves (Lolium perenne) submerged in water at 10,20 and $30{ }^{\circ} \mathrm{C}$. Mean \pm SE (standard error) are depicted.
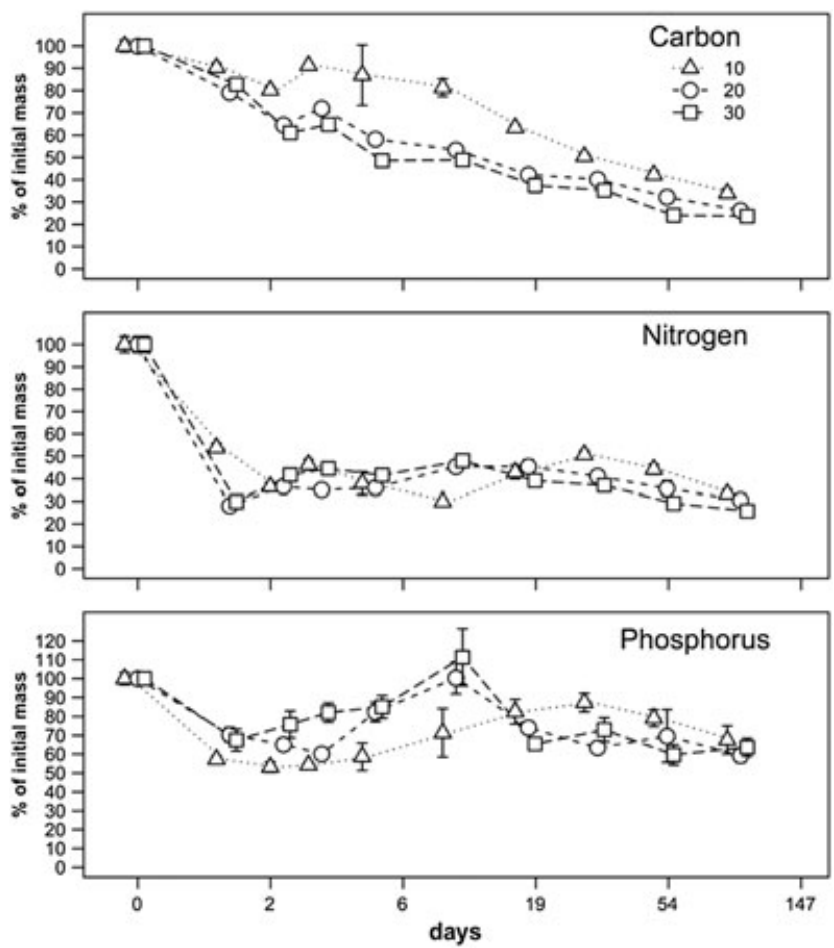

Figure 2. Decomposition patterns of carbon, nitrogen and phosphorus [as $\%$ of initial mass (Table I)] over time (days on a 10-log scale) of Pinkfooted Geese (Anser brachyrhynchus) droppings submerged in water at 10,20 and $30{ }^{\circ} \mathrm{C}$. Mean $\pm \mathrm{SE}$ (standard error) are depicted. in Table II), with a distinct, positive temperature effect on the rate of decomposition ( $K_{\text {lab }}^{T}$ in Table II). At the end of this experiment, more than $60 \%$ of the initial $\mathrm{N}$ and $\mathrm{P}$ was released into the water at all temperatures.

For droppings, $\mathrm{N}$ and $\mathrm{P}$ dynamics followed a more complex pattern with a distinct leaching phase (fast release of $\mathrm{N}$ and $\mathrm{P}$ within the first day), an immobilization phase ( $\mathrm{N}$ and $\mathrm{P}$ uptake, notably in $\mathrm{P}$ ) followed by a mineralization phase ( $\mathrm{N}$ and $\mathrm{P}$ release). Dynamics in $\mathrm{N}$ release at $10{ }^{\circ} \mathrm{C}$ were significantly different from the $\mathrm{N}$ release patterns observed at $20^{\circ} \mathrm{C}$ (Tukey post-hoc test, $P<0.001$ ) and 30 ${ }^{\circ} \mathrm{C}$ (Tukey post-hoc test, $P<0 \cdot 002$ ), whereas difference between $20^{\circ} \mathrm{C}$ and $30^{\circ} \mathrm{C}$ were not significant (Tukey posthoc test, $P=0.965)$. For $\mathrm{P}$, the dynamics at $10{ }^{\circ} \mathrm{C}$ was significantly different only from the $30{ }^{\circ} \mathrm{C}$ pattern (Tukey post-hoc test, $P<0.03$; all other comparisons $P>0.3$ ). During the initial decay period from day 0 to 2 , leaching predominated and about $60 \% \mathrm{~N}$ and $40 \% \mathrm{P}$ entered the water, then $\mathrm{N}$ and $\mathrm{P}$ immobilized, reducing the nutrient losses to approximately $50 \%$ for $\mathrm{N}$ and almost $0 \%$ for $\mathrm{P}$ at the highest temperatures. $\mathrm{N}$ and $\mathrm{P}$ showed net mineralization again at day 30-90 after the onset of the experiment, resulting in losses of up to $60 \%$ for $\mathrm{N}$ and $40 \%$ for $\mathrm{P}$.

\section{DISCUSSION}

The $\mathrm{P}$ and $\mathrm{N}$ release patterns differed for fresh grass leaves and goose droppings and were in accordance with our initial expectations. The goose droppings showed a very rapid initial $\mathrm{N}$ and $\mathrm{P}$ release through leaching, in contrast to the grass leaves where nutrient release patterns followed a more gradual mineralization pattern coupled to the firstorder decay of the organic matter. However, the subsequent immobilization of the released nutrients by bacteria decomposing the droppings eventually resulted in a similar $\mathrm{N}$ release and lower $\mathrm{P}$ release for droppings compared with fresh leaves after approximately 90 days. Temperature had the predicted effect of faster mass loss rates at higher temperatures for both droppings and grass leaves, although the differences in recalcitrant mass loss rates among the 10 , 20 and $30^{\circ} \mathrm{C}$ treatments were not significant.

Mineralization of $\mathrm{P}$ and $\mathrm{N}$ showed similar dynamics for the green leaves, but in the droppings, there were less leaching of $\mathrm{P}$ and a longer period of immobilization and retention for about 30 days. Ultimately, the amount of $\mathrm{P}$ remaining in the droppings was twice as high as in the leaves. This high final $\mathrm{P}$ retention in the droppings was unexpected because if accumulation of remaining droppings occurred in sediment, this would cause enrichment of $\mathrm{P}$ in sediment. The strong immobilization of $\mathrm{P}$ in droppings might be an explanation for the fact that Unckless and Makarewicz (2007) found no increase in nutrient availability after adding droppings to mesocosms. The fact that 
Table II. Parameter estimates for the two-component exponential decay model as applied to the decomposition of organic carbon, nitrogen and phosphorus in grass leaves in water of 10,20 and $30{ }^{\circ} \mathrm{C}$, where $P_{l a b}(\%)$ is the labile fraction percentage, $K_{\text {lab }}\left(d^{-1}\right)$ is the decomposition rate constant of the labile fraction and $K_{\text {rec }}\left(d^{-1}\right)$ is the decomposition rate constant of the recalcitrant fraction (all estimated using Equation (1)). Where a trend was observed in $K_{l a b}$ with temperature, $K_{l a b}$ was replaced by two new parameters, a temperature independent $K_{l a b}^{o}$ and a temperature dependent $K_{l a b}^{T}$ following Equation (2).

\begin{tabular}{|c|c|c|c|c|c|c|c|c|c|c|c|c|}
\hline \multirow{2}{*}{ Temperature $\left({ }^{\circ} \mathrm{C}\right)$} & \multicolumn{4}{|c|}{ Carbon } & \multicolumn{4}{|c|}{ Nitrogen } & \multicolumn{4}{|c|}{ Phosphorus } \\
\hline & & Estimate & $95 \% \mathrm{CI}$ & $\mathrm{P}$ & Estimate & $95 \%$ & $\mathrm{CI}$ & $\mathrm{P}$ & Estimate & $95 \%$ & $\mathrm{CI}$ & $\mathrm{P}$ \\
\hline \multirow[t]{3}{*}{10} & $P_{l a b}$ & $59 \cdot 24$ & $42 \cdot 8475 \cdot 65$ & $<0.001$ & $74 \cdot 83$ & $44 \cdot 85$ & $104 \cdot 80$ & $<0.001$ & $81 \cdot 26$ & $44 \cdot 77$ & $117 \cdot 75$ & $<0.001$ \\
\hline & $K_{r e c}$ & 0.003 & -0.0020 .007 & $0 \cdot 309$ & -0.003 & $-0 \cdot 017$ & $0 \cdot 011$ & 0.635 & $-0 \cdot 008$ & $-0 \cdot 030$ & $0 \cdot 014$ & 0.493 \\
\hline & $K_{l a b}$ & $0 \cdot 058$ & 0.0390 .076 & $<0.001$ & 0.057 & $0 \cdot 024$ & $0 \cdot 090$ & $<0 \cdot 002$ & $0 \cdot 044$ & $0 \cdot 014$ & $0 \cdot 075$ & $<0.006$ \\
\hline \multirow[t]{3}{*}{20} & $P_{l a b}$ & $46 \cdot 08$ & $41 \cdot 37 \quad 50 \cdot 78$ & $<0.001$ & $60 \cdot 99$ & $55 \cdot 17$ & $66 \cdot 82$ & $<0.001$ & $57 \cdot 73$ & $51 \cdot 83$ & $63 \cdot 63$ & $<0.001$ \\
\hline & $K_{r e c}$ & $0 \cdot 011$ & $0.009 \quad 0.013$ & $<0.001$ & $0 \cdot 002$ & -0.001 & $0 \cdot 005$ & $0 \cdot 199$ & $0 \cdot 000$ & $-0 \cdot 003$ & $0 \cdot 004$ & $0 \cdot 850$ \\
\hline & $K_{l a b}$ & $0 \cdot 227$ & 0.1860 .269 & $<0.001$ & $0 \cdot 243$ & $0 \cdot 191$ & $0 \cdot 295$ & $<0.001$ & $0 \cdot 287$ & $0 \cdot 219$ & $0 \cdot 355$ & $<0 \cdot 001$ \\
\hline \multirow[t]{3}{*}{30} & $P_{l a b}$ & $57 \cdot 85$ & $53.8961 \cdot 81$ & $<0.001$ & $66 \cdot 34$ & $62 \cdot 01$ & $70 \cdot 68$ & $<0 \cdot 001$ & $53 \cdot 27$ & 44.98 & $61 \cdot 57$ & $<0 \cdot 001$ \\
\hline & $K_{r e c}$ & $0 \cdot 013$ & 0.0100 .016 & $<0.001$ & $0 \cdot 001$ & -0.003 & $0 \cdot 004$ & 0.690 & $0 \cdot 001$ & $-0 \cdot 005$ & $0 \cdot 008$ & 0.676 \\
\hline & $K_{l a b}$ & $0 \cdot 342$ & 0.2970 .386 & $<0.001$ & $0 \cdot 500$ & 0.410 & $0 \cdot 590$ & $<0.001$ & $1 \cdot 160$ & $0 \cdot 358$ & $1 \cdot 961$ & $<0.007$ \\
\hline \multirow[t]{4}{*}{10,20 and 30 combined } & $P_{l a b}$ & $63 \cdot 13$ & $59 \cdot 6066.66$ & $<0.001$ & $65 \cdot 34$ & $61 \cdot 05$ & 69.63 & $<0 \cdot 001$ & $54 \cdot 68$ & $49 \cdot 36$ & $60 \cdot 01$ & $<0 \cdot 001$ \\
\hline & $K_{\text {rec }}$ & $0 \cdot 004$ & $0.003 \quad 0.006$ & $<0.001$ & 0.000 & -0.002 & 0.003 & 0.707 & $0 \cdot 002$ & $-0 \cdot 001$ & $0 \cdot 005$ & $0 \cdot 180$ \\
\hline & $K_{\text {lab }}^{0}$ & $0 \cdot 019$ & 0.0160 .022 & $<0.001$ & 0.025 & $0 \cdot 018$ & $0 \cdot 032$ & $<0.001$ & $0 \cdot 018$ & $0 \cdot 009$ & $0 \cdot 027$ & $<0.001$ \\
\hline & $K_{l a b}^{T}$ & 0.094 & 0.0860 .102 & $<0.001$ & $0 \cdot 103$ & 0.090 & $0 \cdot 116$ & $<0 \cdot 001$ & $0 \cdot 139$ & $0 \cdot 113$ & $0 \cdot 166$ & $<0.001$ \\
\hline
\end{tabular}

CI, confidence interval.

Table III. Parameter estimates for the two-component exponential decay model as applied to the decomposition of organic carbon and nitrogen in droppings in water of 10,20 and $30{ }^{\circ} \mathrm{C}$, where $P_{l a b}(\%)$ is the labile fraction percentage, $K_{\text {lab }}\left(d^{-1}\right)$ is the decomposition rate constant of the labile fraction and $K_{\text {rec }}\left(d^{l}\right)$ is the decomposition rate constant of the recalcitrant fraction (all estimated using Equation (1)). Where a trend was observed in $K_{l a b}$ with temperature, $K_{l a b}$ was replaced by two new parameters, a temperature independent $K_{l a b}^{o}$ and a temperature dependent $K_{l a b}^{T}$ following Equation (2).

\begin{tabular}{|c|c|c|c|c|c|c|c|c|c|}
\hline \multirow{3}{*}{$\begin{array}{l}\text { Temperature }\left({ }^{\circ} \mathrm{C}\right) \\
10\end{array}$} & \multicolumn{5}{|c|}{ Carbon } & \multicolumn{4}{|c|}{ Nitrogen } \\
\hline & & \multirow{2}{*}{$\begin{array}{c}\text { Estimate } \\
47 \cdot 27\end{array}$} & \multicolumn{2}{|c|}{$95 \%$ CI } & \multirow{2}{*}{$\begin{array}{c}P \\
0.051\end{array}$} & \multirow{2}{*}{$\begin{array}{c}\text { Estimate } \\
59.40\end{array}$} & \multicolumn{2}{|c|}{$95 \%$ CI } & \multirow{2}{*}{$\begin{array}{c}P \\
<0 \cdot 001\end{array}$} \\
\hline & $P_{l a b}$ & & 0.94 & $93 \cdot 61$ & & & $57 \cdot 41$ & $61 \cdot 39$ & \\
\hline & $K_{\text {rec }}$ & 0.005 & -0.006 & $0 \cdot 016$ & $0 \cdot 395$ & 0.001 & 0.000 & 0.002 & 0.705 \\
\hline & $K_{l a b}$ & 0.064 & -0.006 & 0.133 & 0.081 & 1.651 & $1 \cdot 312$ & 1.990 & $<0.001$ \\
\hline \multirow[t]{3}{*}{20} & $P_{l a b}$ & $44 \cdot 24$ & $39 \cdot 37$ & $49 \cdot 11$ & $<0.001$ & - & - & - & - \\
\hline & $K_{\text {rec }}$ & 0.009 & 0.007 & $0 \cdot 012$ & $<0.001$ & - & - & - & - \\
\hline & $K_{l a b}$ & 0.507 & $0 \cdot 362$ & 0.651 & $<0.001$ & - & - & - & - \\
\hline \multirow[t]{3}{*}{30} & $P_{l a b}$ & $51 \cdot 02$ & $45 \cdot 47$ & $56 \cdot 58$ & $<0.001$ & - & - & - & - \\
\hline & $K_{\text {rec }}$ & $0 \cdot 011$ & $0 \cdot 007$ & $0 \cdot 014$ & $<0.001$ & - & - & - & - \\
\hline & $K_{l a b}$ & 0.483 & $0 \cdot 356$ & 0.610 & $<0.001$ & - & - & - & - \\
\hline \multirow[t]{4}{*}{10,20 and 30 combined } & $P_{l a b}$ & $53 \cdot 22$ & $47 \cdot 71$ & $58 \cdot 72$ & $<0.001$ & - & - & - & - \\
\hline & $K_{\text {rec }}$ & $0 \cdot 006$ & $0 \cdot 003$ & $0 \cdot 008$ & $<0.001$ & - & - & - & - \\
\hline & $K_{l a b}^{0}$ & $0 \cdot 020$ & $0 \cdot 012$ & $0 \cdot 027$ & $<0.001$ & - & - & - & - \\
\hline & $K_{l a b}^{T}$ & $0 \cdot 114$ & 0.094 & $0 \cdot 133$ & $<0 \cdot 001$ & - & - & - & - \\
\hline
\end{tabular}

CI, confidence interval.

Only (near) significant models presented (none of the models for phosphorus were significant).

the decomposition of both litter types could better be described by a 'two-component' model indicates that the 'labile' and 'recalcitrant' components indeed behaved differently. The labile-compound decomposition of the leaf material is strongly enhanced by fragmentation and digestion in the goose digestive system. This explains the rapid leaching of nutrients as soon as the droppings come into contact with water. The capacity of immobilizing and retaining nutrients is similar in droppings and leaves for $\mathrm{N}$. For P, however, there was a distinctly higher P immobilization in the droppings, leading to high $\mathrm{P}$ retention in the remnant material.

Incubation temperature has been emphasized as an important environmental factor in many experiments (Hynes and Kaushik, 1969; Carpenter and Adams, 1979; Thullen et al., 2008). In our experiment, decomposition 
rates of the labile component in grass leaves increased from 10 to $30{ }^{\circ} \mathrm{C}$ as was found in many other studies (Iversen, 1975; Carpenter and Adams, 1979; Carvalho et al., 2005). Some studies reported increases (Biasi et al., 2005; Vanhala et al., 2007; Hartley and Ineson, 2008) or no change (Berg et al., 2006; Conen et al., 2006; Czimczik and Trumbore, 2007) in C loss from old soil organic matter composed of recalcitrant components with increasing temperature. However, the decomposition rates of the recalcitrant material from the droppings did not show an increase with temperature change from 10 to $30{ }^{\circ} \mathrm{C}$. It might be possible that digestion by waterfowl accelerated decomposability of grass leaves and caused insensitivity of droppings to relatively higher temperatures.

It should be born to mind that water temperatures in winter may be substantially less than $10{ }^{\circ} \mathrm{C}$ (in The Netherlands closer to $5{ }^{\circ} \mathrm{C}$; Van der Peijl and Verhoeven, 1999). However, because all temperature-dependent decomposition processes followed Equation (2), yielding highly satisfying fits, we are confident that modest extrapolation to temperatures less than $10{ }^{\circ} \mathrm{C}$ and greater than $30{ }^{\circ} \mathrm{C}$ can safely be made using the appropriate parameters in Tables II and III.

Significant differences in decomposition rate existed between grass leaves and droppings. In general, reaction rates, from fastest to slowest, are leaching/autolysis breakdown of labile materials $>$ breakdown of recalcitrant materials (Godshalk and Wetzel, 1978;Brock et al., 1985; Berendse, 1989; Truesdale et al., 2005). The twocomponent exponential decay model served well to describe the decomposition dynamics of fresh grass leaves and droppings, showing the different behaviours of labile and recalcitrant litter fractions. Similar conclusions on the effectiveness of the two-component exponential decay model were reported by Dalias et al. (2001).

In the interpretation of the results of our experiment, it should be recognized that we used small plastic containers with litter submerged in water to estimate decomposition and mineralization rates. In these small containers, the $\mathrm{N}$ and $P$ released accumulated in the water column rather than being diluted and flushed away. This may have resulted in an unrealistically high immobilization of the released $\mathrm{N}$ and $\mathrm{P}$ by the bacterial community decomposing the samples. In future studies, and possibly as another extreme, it might thus be appropriate to also investigate these processes using litterbags in the field, validating and expanding on our results.

Although laboratory incubation will always be an incomplete representation of actual field situations (Webster and Benfield, 1986; Schnitzer and Neely, 2000) and our results largely confirmed our expectations, our study did provide some new insights and is to our knowledge the first to present data on the decomposition and mineralization of droppings in such highly quantitative fashion. The results of our experiment therewith have relevance for the parameterization of nutrient cycling models for lake ecosystems. For example, Hahn et al. (2008) calculated $\mathrm{N}$ and $\mathrm{P}$ inputs to Dutch freshwater lakes by waterfowl of $0.74-1.4 \mathrm{~kg} \mathrm{~N} \mathrm{ha}^{-1} \mathrm{y}^{-1}$ and $0.09-0.10 \mathrm{~kg} \mathrm{P} \mathrm{ha}^{-1} \mathrm{y}^{-1}$ assuming complete release of $\mathrm{N}$ and $\mathrm{P}$ from droppings. However, our data indicate that this may not be a valid assumption. On the basis of the maximum release percentages of $\mathrm{N}$ and $\mathrm{P}$ from droppings in our experiment, we corrected earlier estimates of inputs of Hahn et al. (2008) from waterfowl to Dutch freshwater lakes downwards to $0.52-0.98 \mathrm{~kg} \mathrm{~N} \mathrm{ha}^{-1} \mathrm{y}^{-1}$ and $0.045-0.05 \mathrm{~kg} \mathrm{P}$ $\mathrm{ha}^{-1} \mathrm{y}^{-1}$.

Many biogeochemical models use $\mathrm{C} / \mathrm{N}$ and $\mathrm{C} / \mathrm{P}$ ratios of litter to compute $\mathrm{N}$ and $\mathrm{P}$ mineralization (i.e. Van der Peijl and Verhoeven, 1999; Garnier et al., 2002). Manzoni et al. (2008) also used several simple parameters (initial litter N/ $\mathrm{C}$ ratio, decomposer biomass N/C and its C-use efficiency) to develop universal analytical curves of $\mathrm{N}$ accumulation and release during decomposition assuming decomposer characteristics to be relatively constant in time. Our experiment indicates that such approaches may be too simplistic when dealing with digested material (droppings), which is an important contribution to increasing our understanding of the potential effect of geese and ducks on wetland ecosystem health.

\section{ACKNOWLEDGEMENTS}

We thank Thijs de Boer and Peter de Vries for collecting the plant and faecal material from the field and $\mathrm{Mr}$ Stenenga for allowing them access to his property. Harry Korthals and Paul van der Ven are thanked for their help in setting up the experiment and analysing the samples. This study was supported by the National Natural Science Funds, China, (No. 31370474) and the China Scholar Fund of CAS (2008).

\section{REFERENCES}

Bazel DR, Jefferies RL. 1985. Goose faeces: a source of nitrogen for plant growth in a grazed salt marsh. Journal of Applied Ecology 22: 693-703.

Berendse F. 1989. Comparative study on nutrient cycling in wet heathland ecosystems II. Litter decomposition and nutrient mineralization. Oecologia 78: 338-348.

Berg B, Laskowski R., Caswell H. 2006. Litter Decomposition: A Guide to Carbon and Nutrient Turnover. Elsevier Academic Press: Amsterdam.

Biasi C, Rusalimova O, Meye rH, Kaiser C, Wanek W, Barsukov P, Junger H, Richter A. 2005.Temperature-dependent shift from labile to recalcitrant carbon sources of arctic heterotrophs. Rapid Communications in Mass Spectrometry 19: 1401-1408.

Bremner JM, Mulvaney CS. 1982. Salicylic acid-thiosulphate modification of Kjeldahl method to include nitrate and nitrite. In Methods of Soil Analyses, Part 2: Chemical and Microbiological Properties, Page AC, Miller RH, Keeney DR (eds). Soil Science Society of America: Madison; 621-622. 
Brock TCM., DeLyon MJH, Van Laar EMJM, Van Loon EMM. 1985. Field studies on the breakdown of Nuphar lutea (L.) SM. (Nymphaeaceae), and a comparison of three mathematical models for organic weight loss. Aquatic Botany 21: 1-22.

Carpenter SR, Adams MS. 1979. Effects of nutrients and temperature on decomposition of Myriophyllum spicatum L. in a hardwater eutrophic lake. Limnology and Oceanography 24: 520-528.

Carvalho P, Thomaz SM, Bini LM. 2005. Effects of temperature on decomposition of a potential nuisance species: the submerged aquatic macrophyte Egeria najas planchon. Brazilian Journal of Biology 65 : 51-6.

Chimney MJ, Pietro KC. 2006. Decomposition of macrophyte litter in a subtropical constructed wetland in South Florida (USA). Ecological Engineering 27: 301-321.

Conen F, Leifeld J, Seth B, Alewell C. 2006. Warming mineralises young and old soil carbon equally. Biogeosciences 3:515-519.

Czimczik CI, Trumbore SE. 2007. Short-term controls on the age of microbial carbon sources in boreal forest soils. Journal of Geophysical Research - Biogeosciences 112: G03001.

Dalias P, Anderson JM, Bottner P, Couteaux MM. 2001. Long-term effects of temperature on carbon mineralisation processes. Soil Biology and Biochemistry 33: 1049-1057.

Enwezor WO. 1976. Mineralization of nitrogen and phosphorus in organic materials of varying C-N and C-P ratios. Plant and Soil 44:237-24.

Garnier J, Billen G, Hannon E, Fonbonne S, Videnina Y,Soulie M. 2002. Modelling the transfer and retention of nutrients in the drainage network of the Danube River. Estuar Coast Shelf S 54: 285-308.

Gill JA. 1996. Habitat choice in pink-footed geese: quantifying the constraints determining winter site use. Journal of Applied Ecology 33: 884-892.

Godshalk GL, Wetzel RG. 1978. Decomposition of aquatic angiosperms. III. Zostera marina L. and a conceptual model of decomposition. Aquatic Botany 5: 329-354.

Hahn S, Bauer S, Klaassen M. 2008. Quantification of allochthonous nutrient input into freshwater bodies by herbivorous waterbirds. Freshwater Biology 53: 181-193.

Hartley LP, Ineson P. 2008. Substrate quality and the temperature sensitivity of soil organic matter decomposition. Soil Biology and Biochemistry 40: 1567-1574.

Hynes HBN, Kaushik NK. 1969. The relationship between dissolved nutrient salts and protein production in submerged autumnal leaves. Verh Internat Verein Limnol 17: 95-103.

Iversen TM. 1975. Disappearance of autumn shed beech leaves placed in bags in small streams. Verh Internat Verein Limnol 19: 1687-1692.

Kirschner AKT, Riegl B, Velimirov B. 2001. Degradation of emergent and submerged macrophytes in an oxbow lake of an embanked backwater system: Implications for the terrestrialization process. International Review of Hydrobiology 86: 555-571.

Kitchell JF, Schindler DE, Herwig BR, Post DM, Olson MH, Oldham M. 1999. Nutrient cycling at the landscape scale: The role of diel foraging migrations by geese at the Bosque del Apache National Wildlife Refuge, New Mexico. Limnology and Oceanography 44: 828-836.
Klaassen M, Nolet BA. 2007. The role of herbivorous water birds in aquatic systems through interactions with aquatic macrophytes, with special reference to the Bewick's Swan - Fennel Pondweed system. Hydrobiologia 584: 205-213.

Madsen J, Cracknell G, Fox AD. 1999. Goose populations of the Western Palearctic: a review of status and distribution. Wetlands International Publication No. 48. Wetlands International, The Netherlands, Wageningen. National Environmental Research Institute, Denmark, Ronde.

Manzoni SM, Jackson RB, Trofymow JA, Porporato A. 2008. The global stoichiometry of litter nitrogen mineralization. Science 321: 684-686.

Manzoni SM, Trofymow JA, Jackson RB, Porporato A. 2010.Stoichiometric controls on carbon, nitrogen, and phosphorus dynamics in decomposing litter. Ecological Monographs 80: 89-106.

Mayes E. 1991. The winter ecology of Greenland White-fronted Geese Anser albifrons flavirostris on seminatural grassland and intensive farmland. Ardea 79: 295-304.

Moore TR, Trofymow JA, Prescott CE, Fyles J, Titus BD. 2006. Patterns of carbon, nitrogen and phosphorus dynamics in decomposing foliar litter in Canadian forests. Ecosystems 9: 46-62.

O'Hare MT, Stillman RA, Mcdonnell J, Wood LR. 2007. Effects of mute swan grazing on a keystone macrophyte. Freshwater Biology 52: 2463-2475.

Post DM, Taylor JP, Kitchell JF, Olson MH, Schindler DE, Herwig BR. 1998. The role of migratory waterfowl as nutrient vectors in a managed wetland. Conservation Biology 12: 910-920.

R-Development-Core-Team. 2010. R: a language and environment for statistical computing. R Foundation for Statistical Computing, Vienna, Austria. ISBN 3-900051-07-0, URL http://www.R-project. org.

Schnitzer SA, Neely RK. 2000. Criticism of the litterbag technique for the study of aquatic plant decay: suppression of epiphytic algal biomass. Archives of Hydrobiology 148: 433-440.

Thullen JS, Nelson MS, Cade BS, Sartoris JJ. 2008. Macrophyte decomposition in a surface-flow ammonia-dominated constructed wetland: rates associated with environmental and biotic variables. Ecological Engineering 32: 281-290.

Truesdale VW, Greenwood JE, Rendell AR. 2005. In vitro, batchdissolution of biogenic silica in seawater - the application of recent modelling to real data. Progress in Oceanography 66: 1-24.

Unckless RL, Makarewicz JC. 2007. The impact of nutrient loading from Canada Geese (Branta canadensis) on water quality, a mesocosm approach. Hydrobiologia 586: 393-401.

Van der Peijl MJ, Verhoeven JTA. 1999. A model of carbon, nitrogen and phosphorus dynamics and their interactions in river marginal wetlands. Ecological Modelling 118: 95-130.

Van Eerden MR, Zijlstra M, Van Roomen M, Timmerman A. 1996. The response of Anatidae to changes in agricultural practice: long term shifts in the carrying capacity for wintering waterfowl. Gibier Faune Sauvage 13: 681-706.

Vanhala P, Karhu K, Tuomi M, Sonninen E, Jungner H, Fritze H, Liski J. 2007. Old soil carbon is more temperature sensitive than the young in an agricultural field. Soil Biology and Biochemistry 39: 2967-2970.

Webster JR, Benfield EF. 1986. Vascular plant breakdown in freshwater ecosystems. Annu Rev Ecol Evol S 17: 567-594. 